\title{
Comment on 'Embracing post-fertilisation methods of family planning: a call to action"
}

While acknowledging that the article 'Embracing post-fertilisation methods of family planning: a call to action, ${ }^{1}$ is a personal view, the authors appear to assume that readers of the Journal will agree and be motivated to promote such methods. I would like to voice the view that I and many others would find this unethical. This is a price too high to pay in our desire to help prevent unplanned pregnancies.

\section{Sandra Gordon, MBChB, DRCOG}

Salaried General Practitioner, College Lane Surgery, Pontefract, UK; sandravagordon@googlemail.com

Competing interests None.

J Fam Plann Reprod Health Care 2014;40:73.

doi:10.1136/fprhc-2013-100824

\section{REFERENCE}

1 Raymond EG, Coeytaux F, Gemzell-Danielsson K, et al. Embracing post-fertilisation methods of family planning: a call to action. J Fam Plann Reprod Health Care 2013;39:244-246. 